\title{
Changes in Phenolic Compounds and Cellular Ultrastructure of Arctic and Antarctic Strains of Zygnema (Zygnematophyceae, Streptophyta) after Exposure to Experimentally Enhanced UV to PAR Ratio
}

\author{
Martina Pichrtová • Daniel Remias • Louise A. Lewis • \\ Andreas Holzinger \\ Received: 26 March 2012 / Accepted: 16 July 2012 /Published online: 18 August 2012 \\ (C) The Author(s) 2012. This article is published with open access at Springerlink.com
}

\begin{abstract}
Ultraviolet (UV) radiation has become an important stress factor in polar regions due to anthropogenically induced ozone depletion. Although extensive research has been conducted on adaptations of polar organisms to this stress factor, few studies have focused on semi-terrestrial algae so far, in spite of their apparent vulnerability. This study investigates the effect of UV on two semi-terrestrial arctic strains (B, G) and one Antarctic strain (E) of the green alga Zygnema, isolated from Arctic and Antarctic habitats. Isolates of Zygnema were exposed to experimentally enhanced UV A and B (predominant UVA) to photosynthetic active radiation (PAR) ratio. The
\end{abstract}

\section{Pichrtová}

Department of Botany, Faculty of Science,

Charles University in Prague,

Benátská 2,

12801 Prague 2, Czech Republic

\section{Pichrtová}

Institute of Botany, Academy of Sciences of the Czech Republic,

Dukelská 135 ,

37982 Třeboň, Czech Republic

D. Remias

Pharmacognosy, Institute of Pharmacy, University of Innsbruck, Innrain 80-82,

6020 Innsbruck, Austria

L. A. Lewis

Department of Ecology and Evolutionary Biology,

University of Connecticut,

Storrs, CT 06269-3043, USA

\section{A. Holzinger $(\bowtie)$}

Functional Plant Biology, Institute of Botany,

University of Innsbruck,

Sternwartestr. 15,

6020 Innsbruck, Austria

e-mail: Andreas.Holzinger@uibk.ac.at pigment content, photosynthetic performance and ultrastructure were studied by means of high-performance liquid chromatography (HPLC), chlorophyll $a$ fluorescence and transmission electron microscopy (TEM). In addition, phylogenetic relationships of the investigated strains were characterised using $r b c \mathrm{~L}$ sequences, which determined that the Antarctic isolate (E) and one of the Arctic isolates (B) were closely related, while $\mathrm{G}$ is a distinct lineage. The production of protective phenolic compounds was confirmed in all of the tested strains by HPLC analysis for both controls and UVexposed samples. Moreover, in strain E, the content of phenolics increased significantly $(p=0.001)$ after UV treatment. Simultaneously, the maximum quantum yield of photosystem II photochemistry significantly decreased in UV-exposed strains $\mathrm{E}$ and $\mathrm{G}(p<0.001)$, showing a clear stress response. The phenolics were most probably stored at the cell periphery in vacuoles and cytoplasmic bodies that appear as electrondense particles when observed by TEM after high-pressure freeze fixation. While two strains reacted moderately on UV exposure in their ultrastructure, in strain G, damage was found in chloroplasts and mitochondria. Plastidal pigments and xanthophyll cycle pigments were investigated by HPLC analysis; UVA- and UV B-exposed samples had a higher deepoxidation state as controls, particularly evident in strain B. The results indicate that phenolics are involved in UV protection of Zygnema and also revealed different responses to UV stress across the three strains, suggesting that other protection mechanisms may be involved in these organisms.

\section{Introduction}

Polar regions are characterised by extreme climatic conditions. Organisms living there have to possess adaptations 
that enable them to survive in such a harsh environment. Numerous abiotic stress factors have been connected with polar climate, including low temperature, drought, nutrient limitation and periodic freeze-thaw cycles during the summer [74]. Among those extreme abiotic factors, solar ultraviolet (UV) radiation seems to be not usually considered a major stress factor in polar regions [23, 24]. Solar elevation decreases towards higher latitudes, and therefore, irradiation is lower in polar regions than in temperate and tropical zones. Moreover, solar rays travel a longer path through the atmosphere in getting to the poles, resulting in a greater proportion of shortwave radiation being absorbed and scattered [23]. Over the last few decades and in light of anthropogenically induced ozone depletion, there has been greater interest in the biological effects of UV radiation on polar organisms $[34,49,75]$. It has been hypothesised that certain polar organisms may be unable to adapt to an increasing UV environment. Moreover, predictions for future scenarios allow speculations about an increase of UV radiation reaching the Earth's surface particularly in polar regions. These effects are expected to be further enhanced due to climate change [10].

Many damaging effects caused by UV irradiation have been described, of which the dominant targets are DNA and the photosynthetic apparatus, and secondary effects are caused by the production of reactive oxygen species (ROS) [e.g. 14, 19, 62-67, 76]. Photoautotrophic organisms may be especially threatened by increases in UV radiation because solar radiation is essential for their growth and survival. In polar regions, eukaryotic algae are significant primary producers with the ability to inhabit and even dominate practically all habitats [17]. Recently, extensive research has been performed on the UV resistance of polar algae, especially all marine macroalgae [e.g. 27, 30, 37, 38, $52,53,61]$, and the findings have been reviewed by Hanelt et al. [24], Holzinger and Lütz [29] and Karsten et al. [39]. In general, the resistance to UV stress in macroalgae corresponds to their depth zonation [7].

Few studies have examined the adaptation of polar freshwater or semi-terrestrial algae to UV radiation. This is rather surprising because, in habitats such as shallow pools, these algae are subject to relatively high levels of irradiation, low levels of dissolved organic carbon and low temperatures that slow down repair mechanisms [26]. Apart from that, algae from shallow aquatic localities or semi-terrestrial sites can be additionally subject to desiccation [18, 32, 38]. Additionally, in a study of the arctic soil alga Tetracystis, extraplastidal carotenoids were found, which shield against irradiation [58]. In another study, Holzinger et al. [31] investigated fieldcollected samples of the filamentous Zygnematophyceae, Zygnema sp. from Svalbard (High Arctic). They concluded that this alga was well adapted to ambient conditions of high irradiation and insensitive to experimentally enhanced UV. Similarly, marine intertidal species of the Trebouxiophyceae,
Prasiola crispa [28], and the Ulvophyceae, Ulva sp. [8] and Urospora penicilliformis [61], which need to survive temporarily under almost terrestrial conditions, were also markedly resistant to UV.

Eukaryotic algae possess a range of mechanisms to reduce the impact of UV radiation. In addition to repair mechanisms, protection including UV-screening mechanisms plays an important role. The ability to produce UV-absorbing compounds has two main advantages: First, algae are not limited to the habitats where beneficial physical conditions are available, e.g. dissolved organic carbon or $\mathrm{Fe}^{3+}$ ions, which are able to effectively screen UV $[4,70]$. Second, they are not impaired by nonspecific attenuation of both UV and visible light [14]. Various substances produced by algae with the ability to screen UV radiation are known, for example, mycosporinelike amino acids (MAAs) [13], secondary carotenoids [42], phenolics [60,66] or sporopollenin [78].

The goal of the present study was to describe the effects caused by an enhanced UV to photosynthetic active radiation (PAR) ratio on three selected strains of Zygnema isolated from polar regions. Algae in the genus Zygnema are ideal for such investigations because they grow typically in shallow pools, streamlets or on the surface of wet soils. Moreover, they occur worldwide, including both the Arctic and Antarctica. Even in polar regions, Zygnema is quite common and easy to recognise due to its mat-forming growth $[25,31,40]$. As mentioned, no harmful effect of experimental UV exposure on Zygnema was observed in previous studies [20,31], yet, the nature of UV protection in Zygnema remains unknown. We expect that the alga obtains UV resistance by the accumulation of phenolic compounds, which can be analysed by high-performance liquid chromatography (HPLC). The UV-screening ability of phenolic substances found in some members of the class Zygnematophyceae has already been discussed [18, 60]. Moreover, high amounts of water-soluble pigments, probably also phenolics, have been reported to occur in Zygnema cruciatum [22], but their role in UV screening has not been tested. In this study, we examined if the production of phenolics in Zygnema is enhanced by experimental UV exposure. In addition, we determined pigment contents of chlorophylls and xanthophyll cycle pigment and measured photosystem (PS) II efficiency, and we also observed the ultrastructure of the cells to prove the effectiveness of UV tolerance. Finally, we established the phylogenetic relationships of the three strains of Zygnema according the $r b c \mathrm{~L}$ sequences.

\section{Material and Methods}

\section{Origin of the Strains}

Three strains of Zygnema, originating from the polar regions, were chosen for our experiments. Two of the 
strains, strain B (CCALA 976) and strain G (CCALA 977), were isolated in 2010 on Svalbard (High Arctic) from shallow seepage pools in the Petunia Bay $\left(78^{\circ} 40^{\prime} \mathrm{N}, 16^{\circ} 30^{\prime} \mathrm{E}\right)$ and deposited in the Culture Collection of Autotrophic Organisms in Třebon̆, Czech Republic (CCALA, www.butbn.cas.cz/ccala/index.php). Strain E (CCCryo 278-06) was obtained from the CCCryo culture collection in Potsdam-Golm (cccryo.fraunhofer.de) isolated in 2006 from a meltwater pool north of Artigas Base freshwater lake (also known as Lago Uruguay, Lake Profound or Artigas Base freshwater lake), Fildes Peninsula, Maxwell Bay, King George Island, South Shetland Islands, Antarctica. Prior to the experiment, all strains were cultivated in liquid Bold's basal medium (BBM) [9] at $15{ }^{\circ} \mathrm{C}$ with continuous light regime $\left(\sim 38 \mu \mathrm{mol} \mathrm{m}{ }^{-2} \mathrm{~s}^{-1}\right)$.

\section{DNA Sequencing and Phylogenetic Analysis}

DNA was isolated from the three polar strains of Zygnema (B, E and $\mathrm{G}$ ) using the PowerPlant DNA Isolation Kit (MO BIO Laboratories, Inc., Carlsbad, CA, USA) bacically as described in [36]. Polymerase chain reaction (PCR) amplification of the $r b c \mathrm{~L}$ gene was performed using primers M28F, M1161R or M1390R [43, 47] or with newly designed primers 443F 5'-TCCAAGGTCCTCCTCATGGTATCC-3' and 1263R 5'-ACGGTTTGCACCTGCTCCAGGT-3'. PCR conditions were as listed in [35]. Products of cycle sequencing were analysed on an ABI 3100 DNA SequencerTM (Applied Biosystems, Foster City, CA, USA), with individual reads compiled into contigs in Sequencher 4.5 (Gene Codes Inc., Ann Arbor, MI, USA) and edited manually to resolve any ambiguity. $r b c \mathrm{~L}$ sequences from the study strains of Zygnema were compared to the NCBI database through BLAST searches [3], and the resulting top three matches of each new Zygnema sequence were used to produce an alignment. Published $r b c \mathrm{~L}$ sequences from two members of Desmidiales, Cylindrocystis and Mesotaenium, were used as outgroup. The $r b c \mathrm{~L}$ alignment includes 1,384 nucleotide positions, with a total of 146 parsimony informative sites and 89 parsimony sites for the in-group taxa only. Maximum likelihood (ML) analysis and the ML bootstrap analysis (200 replicates) were performed in PAUP* [72]. The Bayesian analysis was done in Mr. Bayes [33]. The model of sequence evolution used in the ML and Bayesian analyses was selected by jModelTest v0.1 [54] under the Akaike Information Criterion as GTR $+\mathrm{I}+$ gamma. Two independent Bayesian analyses each were run for $1.1 \times 10^{6}$ generations with one cold plus three heated chains, with a subsample frequency of 200. Convergence within and between runs was determined using Tracer v1.4.1 [56]. Trees from the initial $10^{5}$ generations were discarded as burn-in before determining the majority-rule consensus tree.

\section{Experimental Cultivation}

During the experiments, the algae were exposed on agarsolidified BBM [9] plates, three parallel Petri dishes for control and three for UV-exposed samples for each strain. Regularly, a thin layer of liquid medium was added to prevent additional desiccation stress. The dishes were placed into a climate chamber (Percival PGC_6L, USA), with temperature set to $15^{\circ} \mathrm{C}$ and a continuous illumination of $38.1 \pm 3.9 \mu \mathrm{mol}$ $\mathrm{m}^{-2} \mathrm{~s}^{-1}$ (PAR) on average. Subsequently, UV was induced by using a combination of a UV A (Sylvania BL 350, Havells Sylvania, UK; with UVA in the range of 315-400 nm with a peak at $352 \mathrm{~nm}$; for spectrum see the manufacturers web site: www.spezilamp.de/sylvania-mini-lynx-longlife-p-8556.html) and a UV B (LX-363 Drago-lux 12.0, Germany; www.dragon terraristik.de/Technik/Licht-Waerme-UV/DRAGO-LUXDELUXE-COMPACT-120-36-W-24::1793.html) fluorescence tube. Acrylic glass filters (Plexiglas ${ }^{\circledR}$ XT) with a cutoff wavelength of approximately $280 \mathrm{~nm}$ were placed over the UV exposure and an additional filter with a cut-off at approximately $400 \mathrm{~nm}$ over the control samples, respectively. The amount of incident light energy slightly varied within the whole experimental area, that is why the dishes were shifted in a circular manner twice a day to provide overall identical conditions for all replicates. The aim of the exposure was to study the effects caused by enhanced UV/PAR ratio, but not to simulate the spectral proportions of outdoor solar irradiation. Thus, the mean intensities of UV irradiation were $3.22 \pm 1.69 \mathrm{~W} \mathrm{~m}^{-2} \mathrm{UVA}$ and $0.018 \pm 0.015 \mathrm{~W} \mathrm{~m}^{-2} \mathrm{UV}$ B measured with a PMA2100 (Solar Light, USA). This gives a ratio of UV B:UV A of approximately $1: 160$, resulting in a predominant UVA treatment. The UV irradiation was provided for $8 \mathrm{~h} \mathrm{day}^{-1}$. The UV penetrating the cut-off filter was negligible $\left(0.28 \pm 0.25 \mathrm{~W} \mathrm{~m}^{-2} \mathrm{UV}\right.$ A and $\left.0.0003 \pm 0.0002 \mathrm{~W} \mathrm{~m}^{-2} \mathrm{UV} \mathrm{B}\right)$.

\section{Light and Transmission Electron Microscopy}

Potential cellular changes induced by UV stress were observed on the morphological and ultrastructural level. A Zeiss Axiovert 200M Light Microscope (Carl Zeiss AG, Oberkochen, Germany) equipped with a Zeiss Axiocam MRc5 camera was used for capturing micrographs.

Control and 4-day UV-exposed samples were highpressure frozen and freeze-substituted according to the methods of Aichinger and Lütz-Meindl [2] with modifications. Prior to freezing, samples were transferred to $150 \mathrm{mM}$ sucrose for $1 \mathrm{~min}$. Freeze substitution was carried out in $2 \%$ $\mathrm{OsO}_{4}, 0.05 \%$ uranyl acetate in acetone at $-80{ }^{\circ} \mathrm{C}$ for $60 \mathrm{~h}$. Temperature was raised to $-30{ }^{\circ} \mathrm{C}$ at a $\mathrm{d} T$ of $10{ }^{\circ} \mathrm{C} \mathrm{h}^{-1}$ within $5 \mathrm{~h}$ and substitution continued for $4 \mathrm{~h}$ at $-30^{\circ} \mathrm{C}$. Subsequently, temperature was raised to $20{ }^{\circ} \mathrm{C}$ at a $\mathrm{d} T$ of $2.5^{\circ} \mathrm{C} \mathrm{h}^{-1}$ for $20 \mathrm{~h}$, and samples were kept at $20^{\circ} \mathrm{C}$ for $10 \mathrm{~h}$. 
Samples were then transferred to propylene oxide and embedded in low-viscosity embedding resin (Agar Scientific, England). For transmission electron microscopy (TEM), ultrathin sections $(\sim 60 \mathrm{~nm})$ were prepared with a Leica Ultracut, counterstained with uranyl acetate and Reynold's lead citrate and investigated at a Zeiss LIBRA 120 transmission electron microscope at $80 \mathrm{kV}$. Images were captured with a ProScan 2k SSCCD camera.

\section{Photosystem II Efficiency}

The physiological state of the photosynthetic apparatus was determined by measuring the maximum quantum yield of PS II photochemistry in a dark-acclimated state $\left(F_{\mathrm{V}} / F_{\mathrm{M}}\right)$. The samples were taken immediately after the end of the experiment (i.e. after 7 days of exposure to UV/PAR) in five replicates within each of the three Petri dishes $(n=15)$ per strain, dark-adapted for $30 \mathrm{~min}$ and then $F_{\mathrm{V}} / F_{\mathrm{M}}$ was measured with a Handy PEA (Hansatech Instruments, UK).

\section{High-Performance Liquid Chromatography}

Control samples and samples exposed for 7 days to the previously mentioned UV regime were investigated by HPLC. At the end of the experiment, the biomass from individual Petri dishes was filtered onto glass fibre filters (Whatman $\mathrm{GF} / \mathrm{C}$ ), freeze-dried for $48 \mathrm{~h}$ and the dry weight measured. When sufficient biomass could be obtained (strains E and G), two filters were made from each Petri dish $(n=6)$. Only one filter per Petri dish was made for strain B $(n=3)$.

Chlorophylls and carotenoids were quantified by HPLC according to Remias et al. [57]. Briefly, freeze-dried filters were ground with a Micro-Dismembrator (Sartorius) in precooled Teflon jars with a quartz ball and extracted in $\mathrm{N}, \mathrm{N}$ dimethylformamide. After centrifugation and prior to injection, $50 \%$ methanol was added to the extract (1:2). The HPLC system (Agilent ChemStation 1100) was run with a binary solvent gradient and using a LiChroSpher column (RP-C18, $150 \times 4 \mathrm{~mm}$ ). The detection wavelength was $440 \mathrm{~nm}$. Peak assignment was carried out with individual retention times and absorption spectra in comparison to available pigment standards (DHI C14 Centralen, Denmark).

The samples were also screened for polar, soluble phenolics by alternative extraction of the ground cells with methyl tert-butyl ether, followed by phase separation with $20 \%$ methanol. The latter phase was prepared for HPLC injection by centrifugation $(15,000 \times \mathrm{g}, 10 \mathrm{~min})$ and filtration through $0.45 \mu \mathrm{m}$ regenerated cellulose syringe filters. Analysis was performed with the same HPLC system as for pigments, however, using a Phenomenex Synergi Hydro column (RP-C18, $150 \times 2 \mathrm{~mm}$ ) with oven set at $30^{\circ} \mathrm{C}$, pump $0.3 \mathrm{ml} \mathrm{min}{ }^{-1}$, solvent A: water $+0.5 \%$ formic acid, solvent
B: methanol $+0.5 \%$ formic acid. The binary linear gradient was as follows: start $0 \% \mathrm{~B}, 40 \mathrm{~min} 100 \% \mathrm{~B}$ and then $8 \mathrm{~min}$ post-run with $100 \% \mathrm{~A}$. The injection amount was 20 to $40 \mu \mathrm{l}$; typical peaks had retention times between 5 and $25 \mathrm{~min}$. A detection wavelength of $280 \mathrm{~nm}$ was used for semiquantitative peak integration to gain the relative phenol content per sample. The amount of phenolics was calculated as the total peak areas normalised to the algal dry weight.

Data Analyses

Data were analysed using the general linear model (GLM) analysis of variance (ANOVA) with nested design because of the hierarchical structure of the design. The effects of factors 'strain' (B, E and G) and 'UV treatment' (UV and control) were tested. For each factor combination, three Petri dishes were used. Five replicate measurements of $F_{\mathrm{V}} / F_{\mathrm{M}}$ were done in each dish and one to two filters were prepared from each dish for the HPLC analysis. Therefore, the effect of individual Petri dishes was nested in 'strain'. 'Petri dish' was considered as a random effect factor and both 'strain' and 'UV treatment' were considered as factors with fixed effects. When significance of an effect was proved by GLM ANOVA, additional Tukey's test was performed for post hoc pairwise comparisons. All statistical analyses were performed in Statistica for Windows, Version 10, Statsoft.

\section{Results}

\section{Molecular Characterisation}

The $r b c \mathrm{~L}$ sequences of the three new Zygnema strains were deposited in GenBank under accession numbers JX075101 (strain B), JX075102 (strain E) and JX075103 (strain G). The sequences obtained were 721 (strain G), 1,302 (strain B) and 1,358 (strain E) nucleotides in length. Phylogenetic analysis of the new $r b c \mathrm{~L}$ data with related published $r b c \mathrm{~L}$ sequences (Fig. 1) demonstrated that strains B and E are closely related (they differ by seven nucleotides, representing $0.5 \%$ difference overall) and together are related to a strain of Zygnema cf. insigne isolated by John Hall (JH0007) [71]. The strain Zygnema sp. G is in a separate clade from strains B and E, and instead is most closely related to Zygnema peliosporum (UTEX LB45). The distinction of strains $B$ and $E$ from $G$ is supported strongly by both ML bootstrap and Bayesian analysis (Fig. 1).

\section{Light Microscopy}

All three investigated strains had typical Zygnema appearance with two star-shaped chloroplasts per cell, each containing a pyrenoid in the centre of the chloroplast (Fig. 2a, c). All 


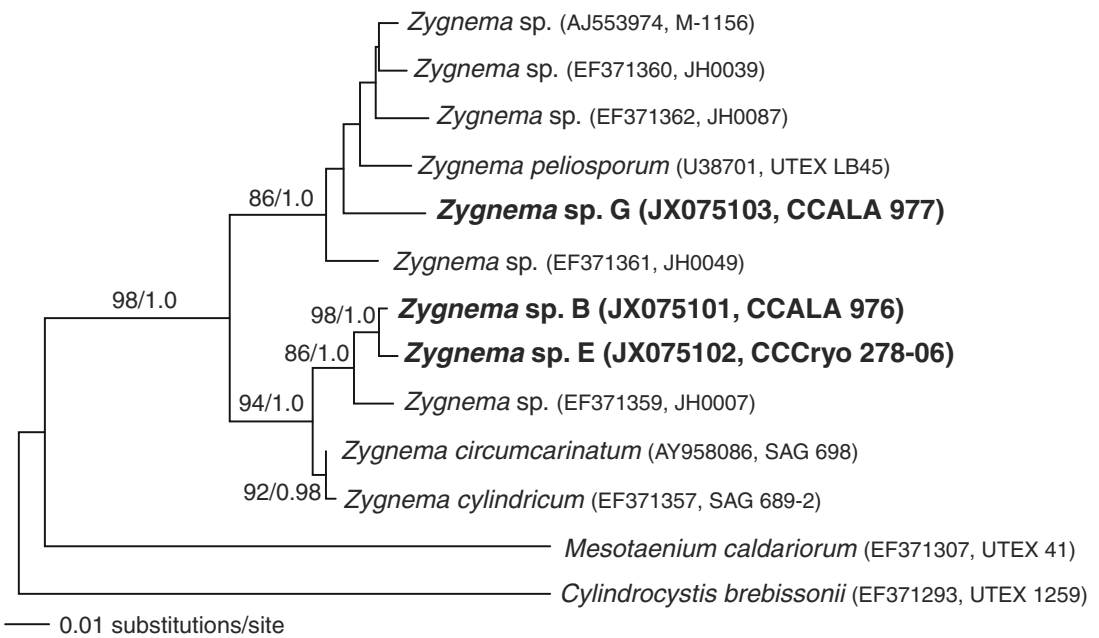

Figure $1 \mathrm{ML}$ tree (score $-\operatorname{lnL}=4,104.333$ ) from phylogenetic analysis of $r b c \mathrm{~L}$ sequence data from different strains of Zygnema plus two related saccoderm desmid genera. Taxon labels include GenBank accession numbers and strain designations. Labels listed in boldface font were obtained for this study. The GTR+gamma model parameter values were set during the search: RA-C $=3.0900652$; $\mathrm{RA}-\mathrm{G}=7.7050449$; RA-T= 7.7120372; $\mathrm{RC}-\mathrm{G}=2.7439213$; $\mathrm{RC}-\mathrm{T}=28.160416$; $\mathrm{RG}-\mathrm{T}=1$; gamma shape $=0.813032 ;$ pinvar $=0.441081$. ML bootstrap support values (out of 200 replicates) are indicated, followed by Bayesian posterior probabilities. Scale bar corresponds to the number of expected substitutions/site
Figure 2 Light microscope images of the investigated Zygnema strains. a strain Bcontrol, b strain B-after UV exposure, $\mathbf{c}$ strain E-control, $\mathbf{d}$ strain E-UV exposure, e strain $\mathrm{G}$ - control, f strain $\mathrm{G}$ - UV exposure. Scale bars, $10 \mu \mathrm{m}$
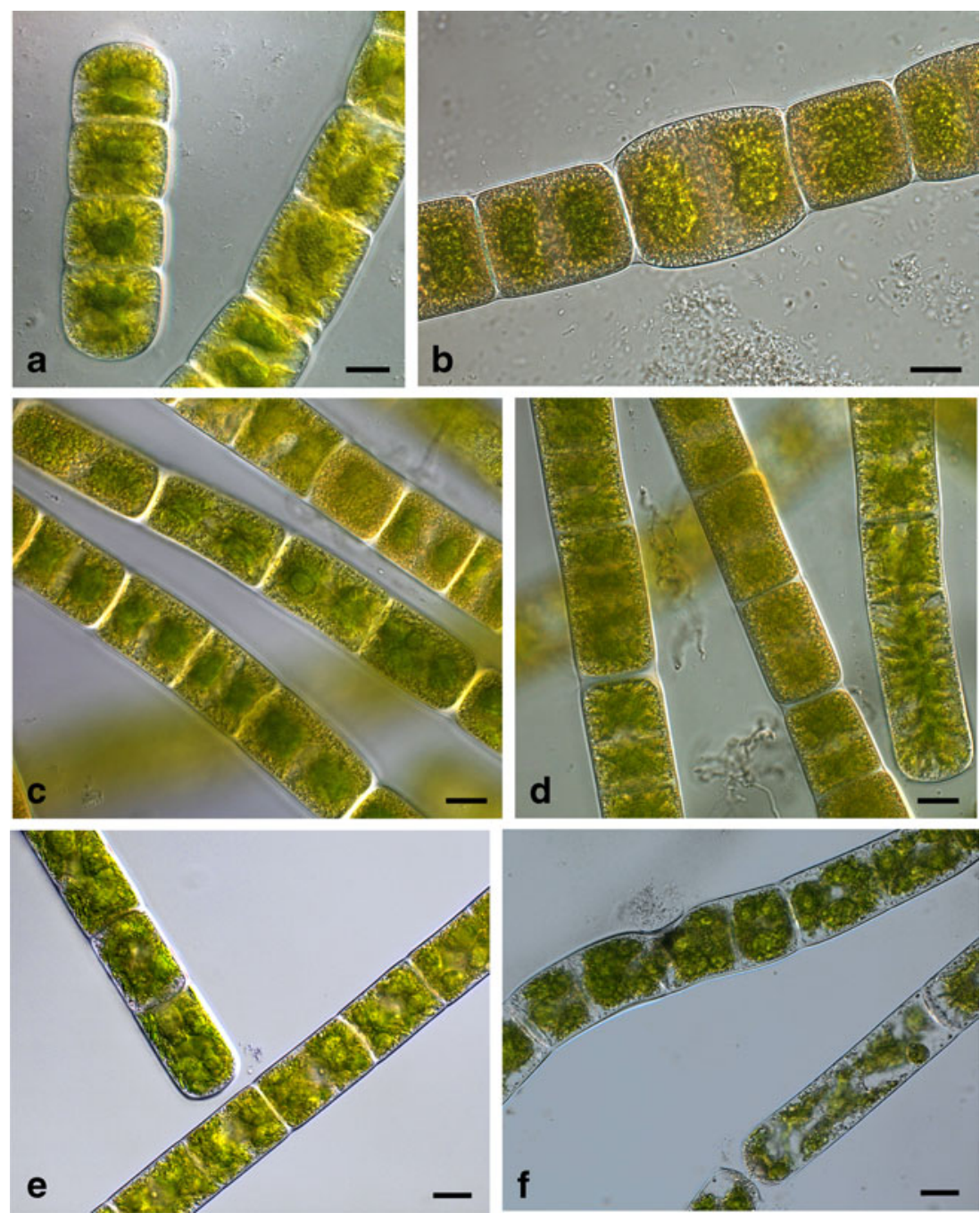
samples, including PAR-only, had a remarkably dense cytoplasm with chloroplasts practically filling up the whole intracellular space. In strain B, the cells were considerably browner after UV treatment (Fig. 2b), which could be a result of an increased number of vacuoles at the cell periphery. On the other hand, there was no visible difference between control and UV-treated cells in strain E, both cultures appeared similar; UV-exposed samples remained unaltered (Fig. 2c, d). On the contrary, in strain G, obvious damages could be observed after UV exposure (Fig. 2f). Most of the cells lost their cytoplasmic streaming completely and chloroplasts disintegrated into smaller, often globular pieces.

\section{Transmission Electron Microscopy}

When viewed by TEM, Zygnema sp. B showed star-shaped chloroplasts in the centre of the cells (Fig. 3a). The chloroplasts had a central pyrenoid with starch grains and several lobes protruding towards the cell periphery (Fig. 3a). In the cell periphery, medium electron-dense compartments and electron-dense particles were observed (Fig. 3a, c, d) and small vacuoles were found (Fig. 3a, d). Mostly in close vicinity of the chloroplast, Golgi bodies with at least 10 cisternae were visible (Fig. 3b). At the Golgi bodies, a clear distinction between cis- and trans-side was possible, the latter giving rise to the trans-Golgi network (TGN; Fig. 3b). The cell centre contained a nucleus (Fig. 3c) with a marked nucleolus. The vacuoles in the cell periphery were polymorphic (Fig. 3c, d); electron-dense particles had a diameter of approximately $400-600 \mathrm{~nm}$ (Fig. 3d). Close to the nucleus, microtubules were occasionally observed; mitochondria showed an internal structure with cristae (Fig. 3e). When Zygnema sp. B cells were exposed to UV, only little modifications of the ultrastructure were observed (Fig. 4). The chloroplast lobes covered medium electron-dense compartments, and electron-dense particles were still evident (Fig. 4a, b). However, the amount of vacuolisation increased (Fig. 4b). In general, neither Golgi bodies nor mitochondria were altered (Fig. 4c). The chloroplast still contained starch grains (Fig. 4c); only occasionally electron-dense spots were observed within the chloroplast lobes (Fig. 4d).

Zygnema sp. E control cells (Fig. 5) had particularly long and narrow chloroplast lobes, covered by large medium electron-dense compartments. Electron-dense particles and
Figure 3 Details of the ultrastructure of control cells of Zygnema sp. B. a Star-shaped chloroplast in the centre of the cell, medium electron-dense compartments (asterisks) and electron-dense particles (arrows) at the cell periphery; b Golgi bodies in close contact with chloroplast, a TGN is clearly visible (arrows); c cell periphery with medium electron-dense compartments (asterisk), nucleus in the centre of the cell; $\mathbf{d}$ multiple shapes of medium electron-dense compartments (asterisks) and electron-dense particles (arrows); e microtubules (arrows) close to the nucleus and mitochondrion. Chl chloroplast, $C W$ cell wall, $G$ Golgi bodies, $M$ mitochondrion, $N$ nucleus, $P y$ pyrenoid. Scale bars: a, c $2 \mu \mathrm{m} ; \mathbf{b}, \mathbf{d} 1 \mu \mathrm{m}$; e $500 \mathrm{~nm}$
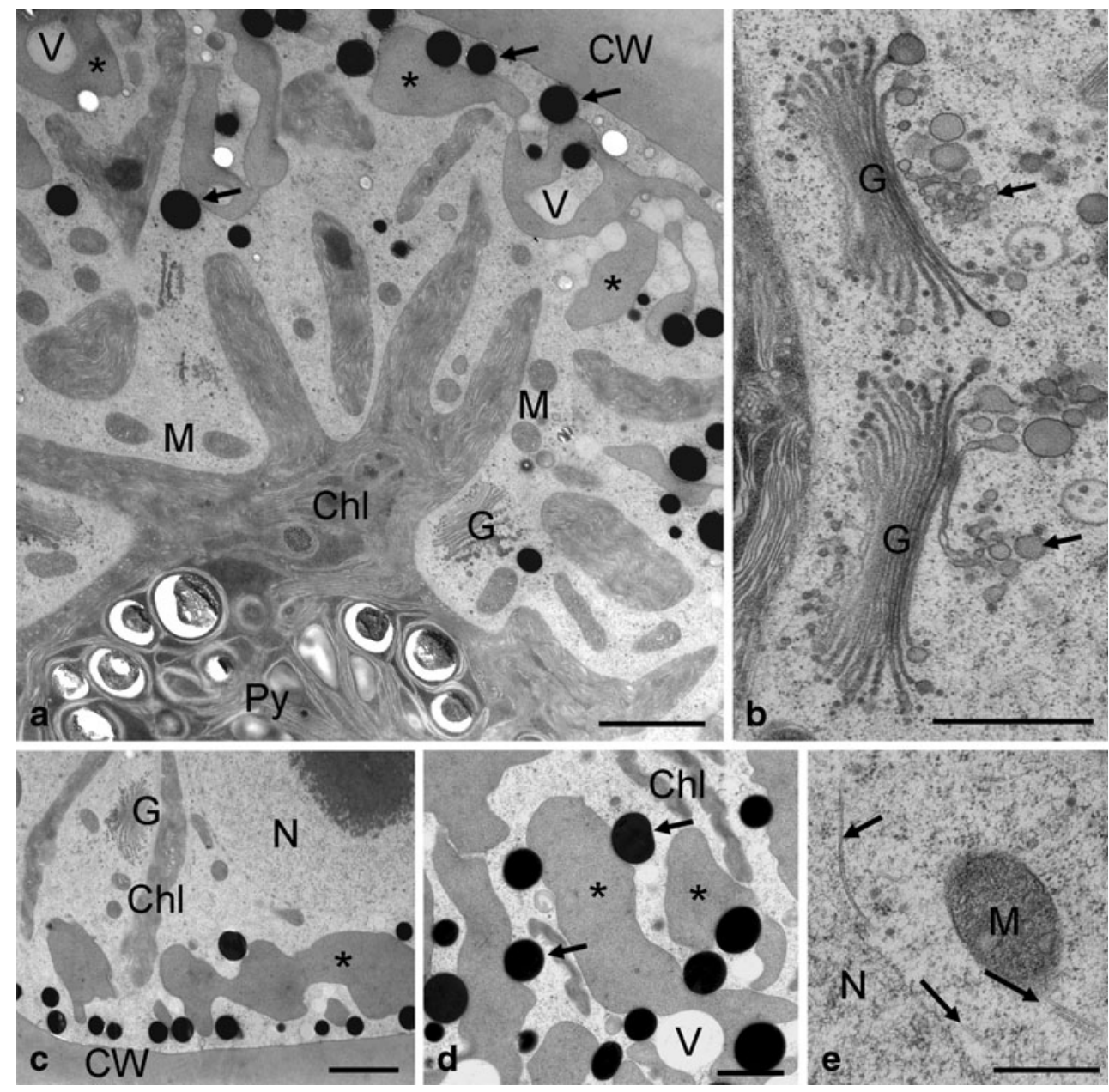
Figure 4 Transmission electron micrographs of Zygnema sp. B after UV exposure. a Chloroplast lobes, Golgi bodies, medium electrondense compartments (asterisk) and electron-dense particles (arrow) appear unchanged; b while medium electron-dense compartments (asterisks) and electron-dense particles (arrows) appear unchanged, additional occurrence of electron-translucent vacuoles was found; c Golgi body with normal appearance, chloroplast with starch grain; d unchanged mitochondria, chloroplast lobe with electron-dense inclusion (arrow). Chl chloroplast, $\mathrm{CW}$ cell wall, $G$ Golgi bodies, $M$ mitochondria, $S$ starch grain $V$ vacuole. Scale bars: a-d $1 \mu \mathrm{m}$
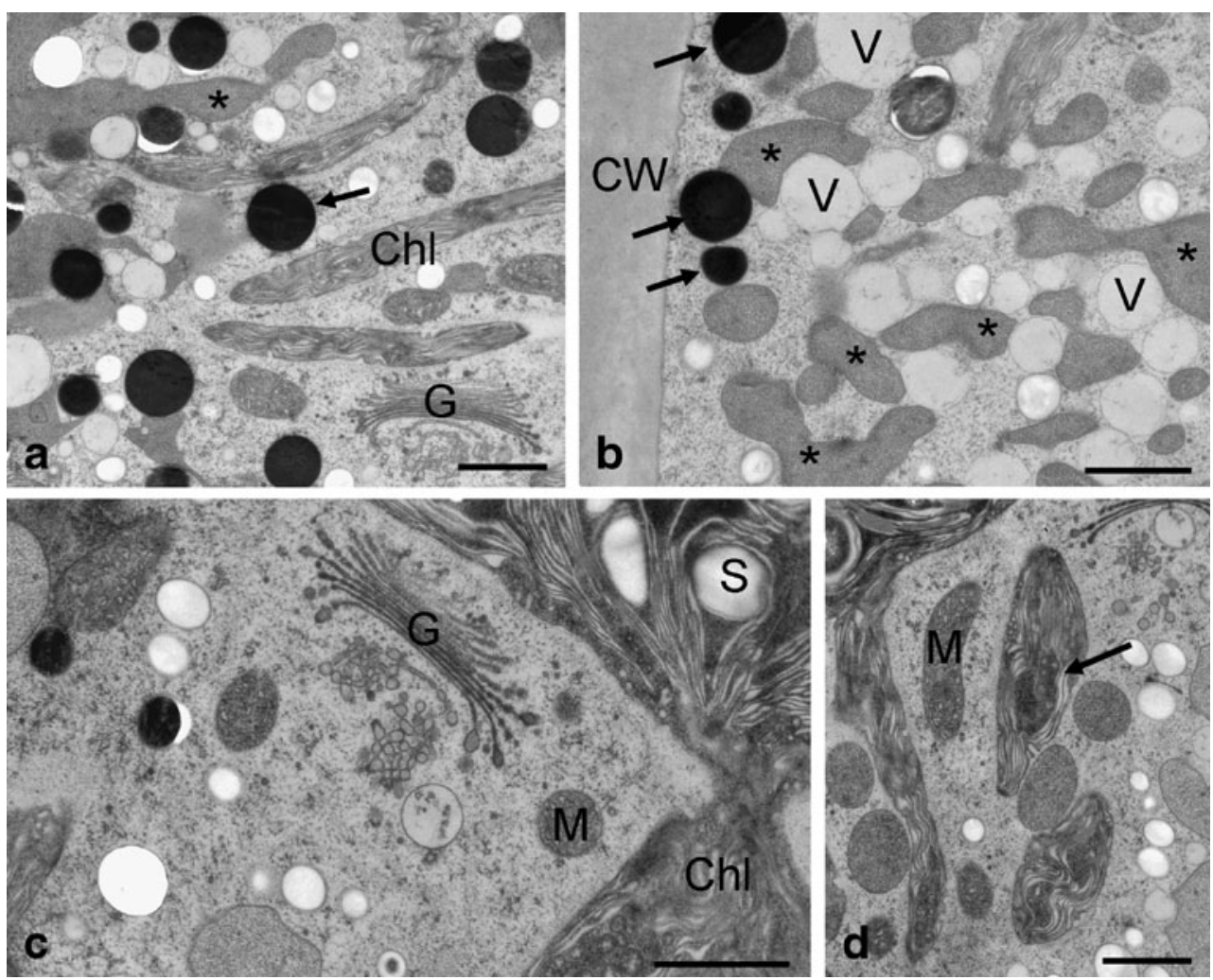

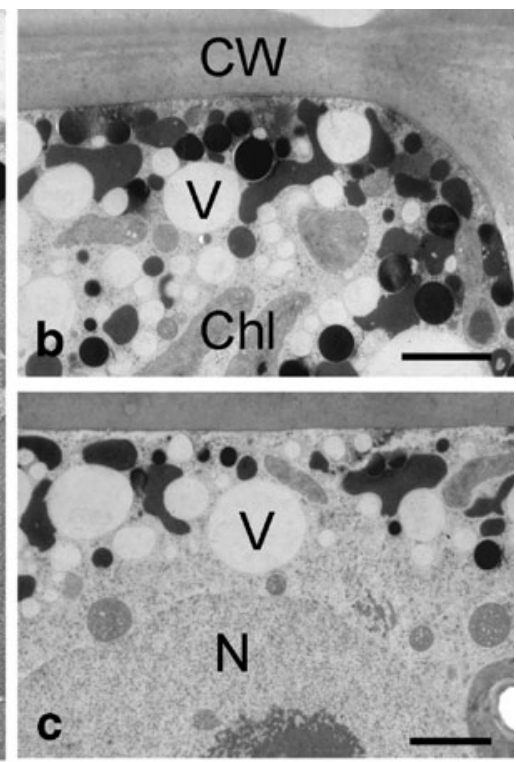

Figure 5 Details of the ultrastructure of control cells of Zygnema sp. E. a Long and narrow chloroplast lobes covered by large medium electron-dense compartments (asterisks) and electron-dense particles (arrow); b cortical area with electron-dense particles and vacuoles; c central area of the cell with nucleus and part of the nucleolus (arrow), vacuoles in the cell cortex; $\mathbf{d}$ chloroplast detail with pyrenoid, mitochondria and nucleus; e detail with Golgi bodies, mitochondria and chloroplast lobes. Chl chloroplast, $C W$ cell wall, $G$ Golgi body, $M$ mitochondrion, $N$ nucleus, $P y$ pyrenoid, $V$ vacuole. Scale bars: a, d, e $1 \mu \mathrm{m} ; \mathbf{b}, \mathbf{c}$ $2 \mu \mathrm{m}$
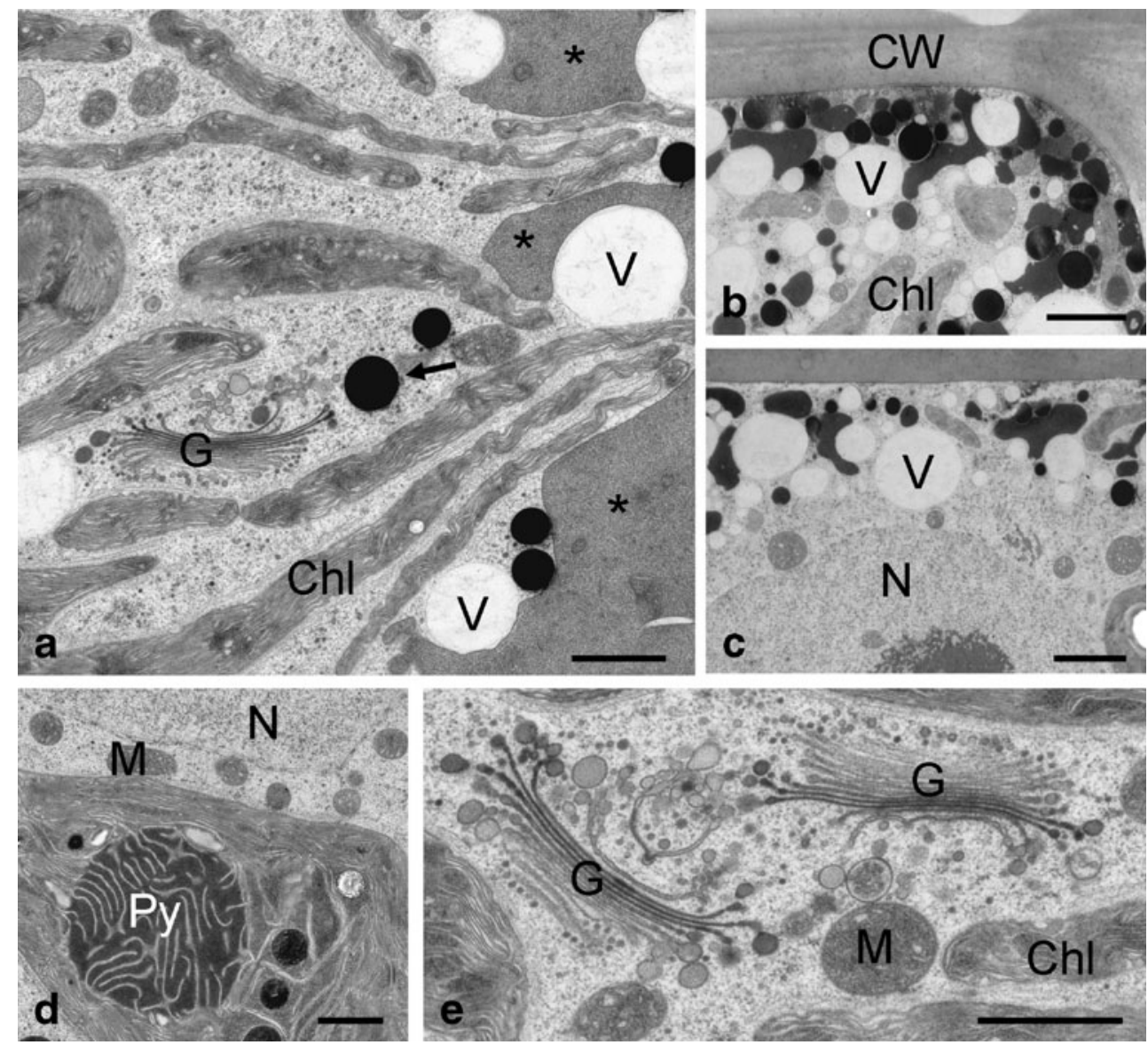
electron-translucent vacuoles were also observed in the cell periphery (Fig. 5a, b). The nucleus showed a distinct nucleolus, which is shown in part in Fig. 5c. The pyrenoid had a characteristic shape, with thylakoid membranes penetrating the central electron-dense area (Fig. 5d). Golgi bodies (Fig. 5e) were similar to those described for Zygnema sp. B. Upon exposure of Zygnema sp. E to UV radiation, again, no drastic changes of the ultrastructure were observed (Fig. 6). Medium electron-dense compartments, vacuoles and electron-dense particles remained in the cell periphery. Golgi bodies and mitochondria remained intact (Fig. 6a). Only occasionally, chloroplasts showed accumulations of plastoglobules or electron-dense areas (Fig. 6b, c). The nucleus remained visibly intact with one nucleolus (Fig. 6b). In some cases, particularly large vacuoles were observed (Fig. 6d).

While Zygnema sp. G control cells (Fig. 7a-c) had a similar appearance as the previously mentioned control cells, the exposure to UV lead to more drastic consequences in this strain (Fig. 7d-f). Control cells contained narrow chloroplast lobes between medium electron-dense compartments, electron-dense particles and vacuoles (Fig. 7a). Nucleus, mitochondria and Golgi bodies had the expected appearance in TEM control samples
(Fig. 7b, c). Zygnema sp. G exposed to UV showed swellings of the chloroplasts with plastoglobules and partially electron-dense areas (Fig. 7d, f); mitochondria were particularly electron-dense and showed a rearrangement of cristae (Fig. 7e).

\section{Photosystem II Efficiency}

The mean values of the maximum quantum yield of PS II $\left(F_{\mathrm{V}} / F_{\mathrm{M}}\right)$ were substantially lower after UV exposure than in the control (Fig. 8). However, the response to UV differed among the tested strains, and this decrease was significant only in strain E and strain G. The results of the statistical analyses testing the difference of measured values of $F_{\mathrm{V}} / F_{\mathrm{M}}$ are presented in Table 1; the pairwise comparisons confirmed the significant difference between control and exposure in strain $\mathrm{E}(p<0.001)$ and strain $\mathrm{G}(p<0.001)$, but not in strain $\mathrm{B}(p=0.086)$. For comparison of the values in individual strains, see Fig. 8.

Interestingly, $F_{\mathrm{V}} / F_{\mathrm{M}}$ differed significantly among individual controls as well, showing a considerable level of stress response even without experimental UV treatmentmost pronounced in strain G. Apparently, this strain was already impaired under control conditions. Low values
Figure 6 Transmission electron micrographs of Zygnema sp. E after UV exposure. a Detail of the cell cortex with chloroplast lobes, substantial amount of vacuolisation, medium electron-dense compartments (asterisks) and electron dense particles (arrows); b central area, nucleus with nucleolus, mitochondria intact, the chloroplasts contain electrondense areas and plastoglobules (arrow); c mitochondria with normal appearance, chloroplast partly swollen; $\mathbf{d}$ extensive medium electron-dense compartments (asterisks) in the cell cortex, vacuoles and chloroplast lobes are found in the same area. $C h l$ chloroplast, $C W$ cell wall, $G$ Golgi body, $L$ lipid body, $M$ mitochondrion, $V$ vacuole. Scale bars: a-d $1 \mu \mathrm{m}$
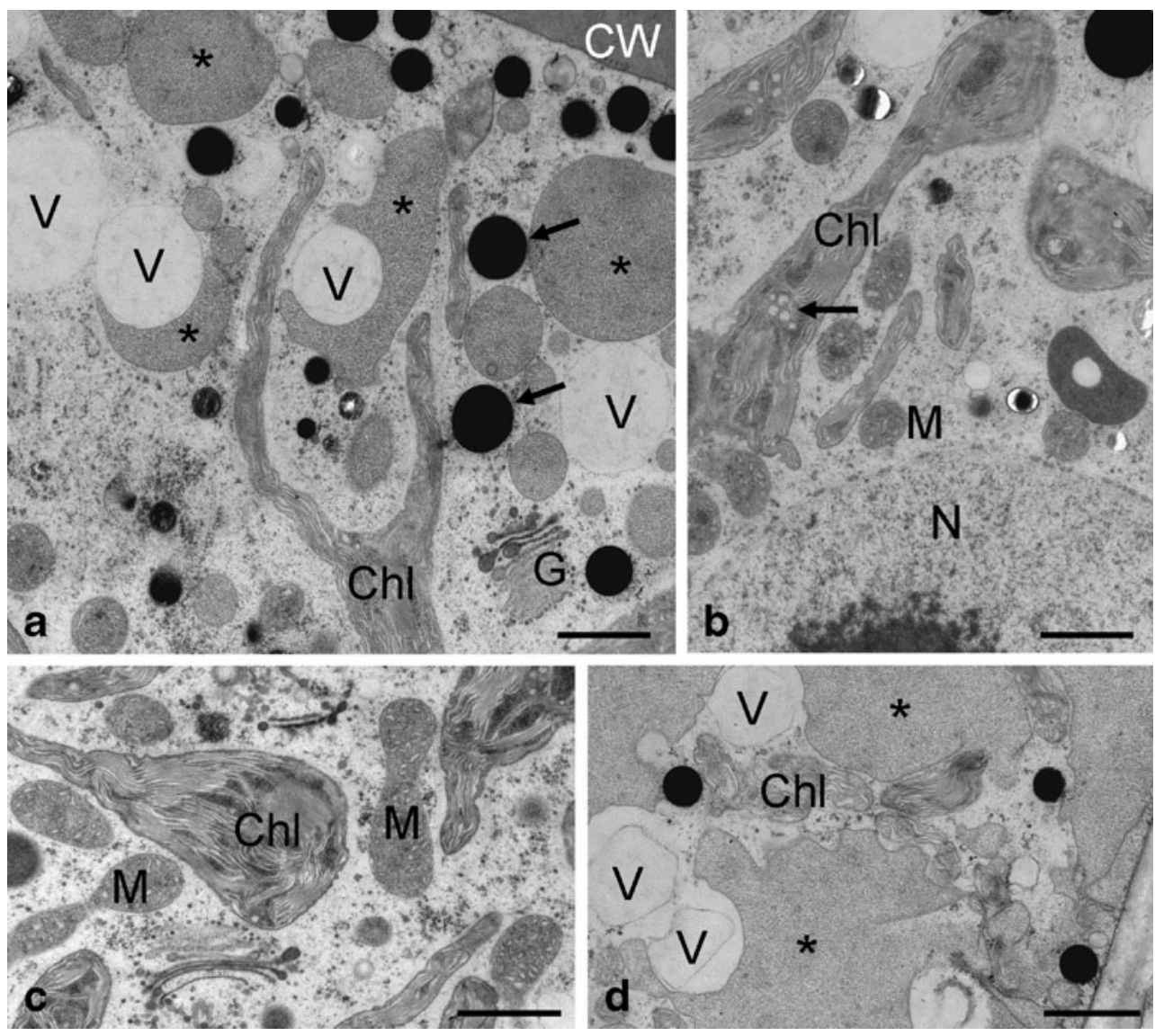
Figure 7 Details of the ultrastructure of Zygnema sp. G control cells $(\mathbf{a}-\mathbf{c})$ and cells after UV exposure $(\mathbf{d}-\mathbf{f})$. a Chloroplast lobes between medium electron-dense compartments (asterisks), vacuoles and electron-dense particles (arrow) in the vicinity of the cell wall; b central area with nucleus and mitochondria; $\mathbf{c}$ Golgi body next to a chloroplast lobe and medium electrondense compartment (asterisk); $\mathbf{d}$ cortical area with altered chloroplast with swellings (arrows), partially filled with electrondense content or plastoglobules, medium electron-dense compartment (asterisk); e altered mitochondria with rearranged parallel-oriented cristae (arrow); f chloroplast with electron-dense contents (arrows). Chl chloroplast, $C W$ cell wall, $G$ Golgi body, $M$ mitochondrion, $N$ nucleus Scale bars: a-f $1 \mu \mathrm{m}$
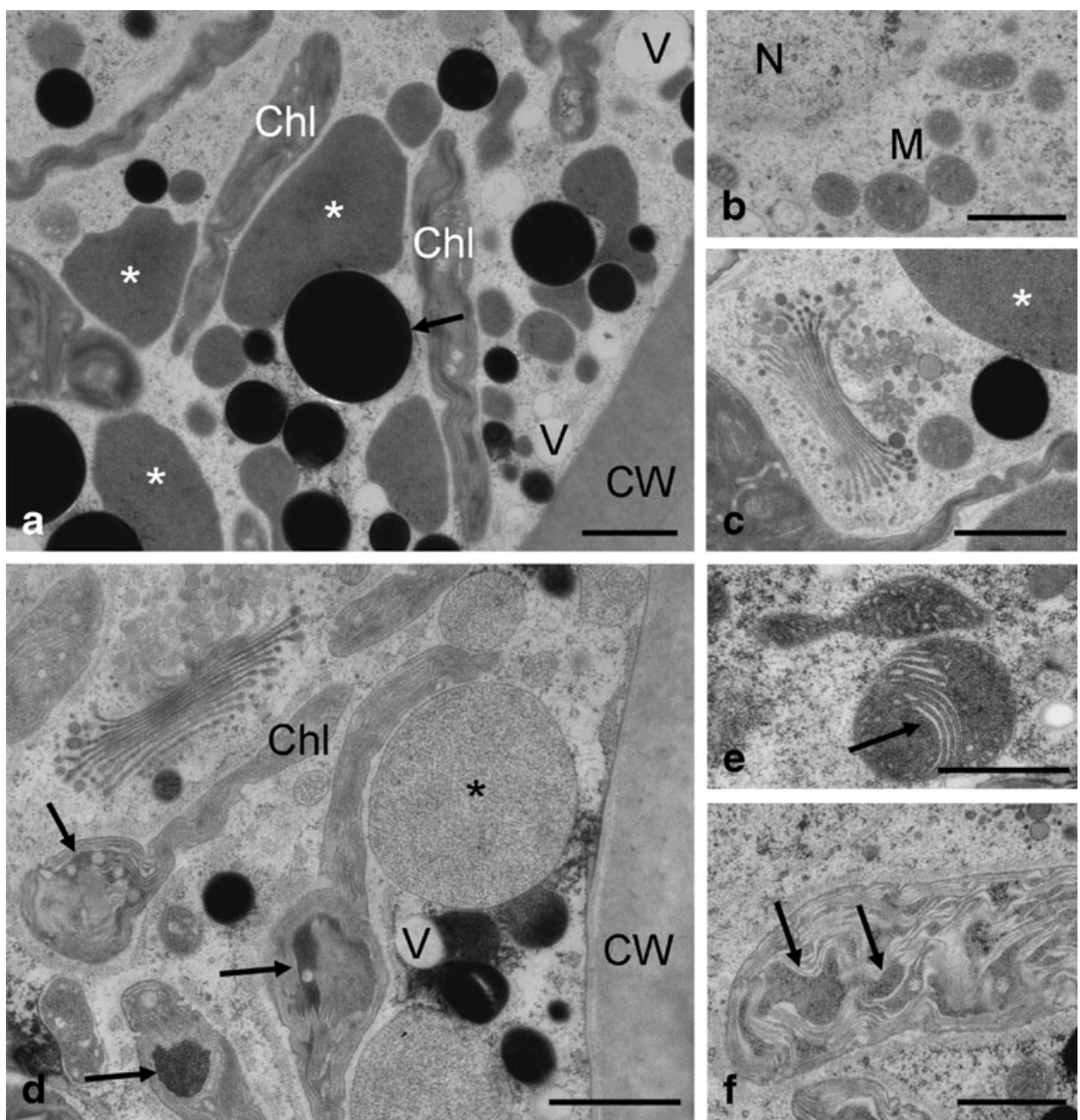

(around 0.2) measured after UV exposure indicated that the photosystems were practically destructed.

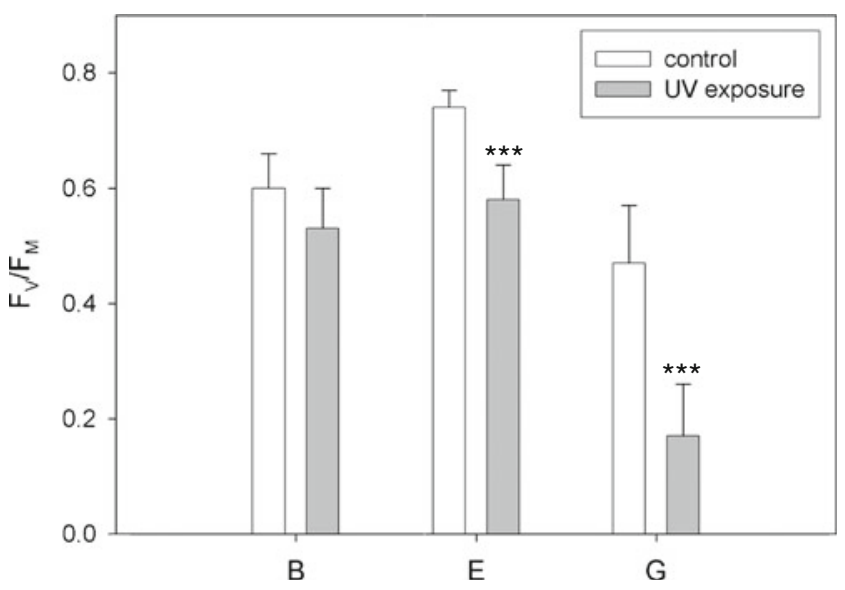

Figure 8 Maximum quantum yield of PS II in dark-adapted state for both control and UV-exposed samples; mean values +SD. Significant differences $(p<0.001)$ between control and UV-exposed samples were found in strains $\mathrm{E}$ and $\mathrm{G}$ and are marked with three asterisks $(n=15)$

\section{Plastidal Pigments}

The content of plastid-bound pigments was measured by HPLC. The pigments were categorised into three groups: First, chlorophyll $a$ and $b$, including some degenerative phaeophytin derivates, which occurred in several samples; second, xanthophyll cycle pigments, i.e. violaxanthin (V), antheraxanthin (A) and zeaxanthin $(\mathrm{Z})$; and third, the remaining primary carotenoids, including beta-carotene, lutein and neoxanthin. Finally, the deepoxidation state of xanthophyll cycle $(\mathrm{A}+\mathrm{Z}) /(\mathrm{V}+\mathrm{A}+$ Z) was estimated.

Neither of the investigated group of pigments differed significantly between controls and UV-exposed samples (Table 1). However, the total pigment content per dry weight was significantly lower in strain B than in the other two strains (Table 2; $p<0.005$ ). Therefore, the relative pigment compositions for each individual strain are presented (Fig. 9).

When viewed from the deepoxidation state of the cultures, significant differences were revealed between UV- 
Table 1 Summary of the results of statistical analyses (GLM, $p$ values of nested ANOVA)

\begin{tabular}{lcrccccc}
\hline Effect & $d f$ & $F_{\mathrm{V}} / F_{\mathrm{M}}$ & Total phenolics & Chlorophylls $a+b$ & $\mathrm{~V}+\mathrm{A}+\mathrm{Z}$ & Other primary carotenoids & Deepoxidation state \\
\hline UV treatment & 1 & $<0.0001$ & 0.0012 & 0.9884 & 0.0813 & 0.2829 & 0.0473 \\
Strain & 2 & 0.0001 & 0.0037 & 0.0816 & 0.0058 & 0.0129 & 0.0022 \\
Petri dish (strain) & 6 & 0.0319 & 0.5595 & 0.15 & 0.3896 & 0.2545 & 0.3961 \\
Strain $\times$ treatment & 2 & $<0.0001$ & 0.0404 & 0.9163 & 0.7539 & 0.3247 & 0.0776 \\
\hline
\end{tabular}

'UV treatment' and 'strain' were considered as fixed effects, 'Petri dish' was considered as a random effect

Petri dish (strain) Petri dish nested in strain, $F_{V} / F_{M}$ PS II efficiency, $V+A+Z$ xanthophyll cycle pigments, Deepoxidation state the ratio $(\mathrm{A}+\mathrm{Z}) /(\mathrm{V}+\mathrm{A}+\mathrm{Z})$

treated samples and controls (Table 1), showing that the UV samples were in higher deepoxidation state than the controls. The individual strains differed as well, as strain $\mathrm{G}$ was significantly more deepoxidised than the other two (Tables 1 and 2). Finally, virtually no secondary carotenoids were detected by using the same HPLC protocol as for pigment analysis.

\section{Phenolic Compounds}

By HPLC, all three Zygnema strains showed the presence of several compounds with the ability to screen UV radiation. The putative phenolic nature of these peaks was derived from their characteristic spectral absorption maxima around $280 \mathrm{~nm}$ typical for aromatic compounds and also from their water-soluble, hydrophilic nature.

The mean values of the content of phenolic compounds were always higher in UV-exposed samples than in the controls (Fig. 10a), but the effect of UV was different among individual strains. The detailed results of statistical tests can be seen in Table 1. Markedly, the pairwise comparisons clearly showed the difference between control and exposure to be significant within only one of the strains tested - strain E $(p=0.001)$. In general, strain B possessed fewer phenolics per dry weight than the other two strains. Furthermore, the same phenolics were present also in control samples, suggesting that certain amounts of protective compounds are present independently of environmental UV stimuli. Figure 10a illustrates the summarised peak areas of the phenolics for each species and their increase after UV exposure.
Figure 10b demonstrates a representative HPLC chromatogram with the phenolic peaks of Zygnema strain $\mathrm{E}$ after exposure. The first and the last main peaks (retention times, 6.57 and $18.823 \mathrm{~min}$ ) have HPLC-online absorption maxima of approximately $278 \mathrm{~nm}$, thus absorbing mainly UV B radiation. Two further main peaks (8.356 and $16.141 \mathrm{~min}$ ) show an additional absorption in the UV A region (shoulder at $352 \mathrm{~nm}$ and a minor maximum at $367 \mathrm{~nm}$, respectively). The second peak (retention time 8.356) can be even seen in the visible (VIS) light region with a minor maximum at $473 \mathrm{~nm}$. This fact corresponds most likely with the yellowish colour of the aqueous extracts. All the minor peaks had similar absorption spectra. The control samples contained all these compounds as well, however, in lower concentrations per dry weight. The other two species had very similar chromatograms (data not shown).

\section{Discussion}

We investigated the effect of UV on the cell structure and ultrastructure, the physiological performance and the production of intracellular soluble compounds in three polar strains of Zygnema. All strains were isolated from polar habitats and, therefore, a comparable level of stress resistance could be speculated about. After UV irradiation, we found a significant increase in accumulation of phenolic compounds in strain $\mathrm{E}$ and a significant decrease in PS II efficiency in strains $E$ and $G$, when compared to control cells. Both effects are stress responses, however, occurring to a different extent in the investigated strains.
Table 2 Total pigment content of the investigated strains of $Z y g$ nema (in micrograms per gram dry weight) and deepoxidation state $(\mathrm{A}+\mathrm{Z}) /(\mathrm{V}+\mathrm{A}+\mathrm{Z})$

Mean values are given as well as standard deviations

\begin{tabular}{|c|c|c|c|c|c|c|}
\hline \multirow{2}{*}{$\begin{array}{l}\text { Strain } \\
\text { Treatment }\end{array}$} & \multicolumn{2}{|l|}{ B } & \multicolumn{2}{|l|}{$\mathrm{E}$} & \multicolumn{2}{|l|}{ G } \\
\hline & Control & UV & Control & UV & Control & UV \\
\hline Total pigment-mean & 0.8076 & 0.8750 & 2.8083 & 2.7018 & 2.5265 & 3.0529 \\
\hline Total pigment- $-\mathrm{SD}$ & 0.3834 & 0.1060 & 0.7915 & 1.1058 & 1.3739 & 0.6734 \\
\hline Deepoxidation state - mean & 0.2947 & 0.5926 & 0.4320 & 0.4615 & 0.7814 & 0.7707 \\
\hline Deepoxidation state-SD & 0.1139 & 0.1058 & 0.0710 & 0.0700 & 0.0253 & 0.2015 \\
\hline
\end{tabular}




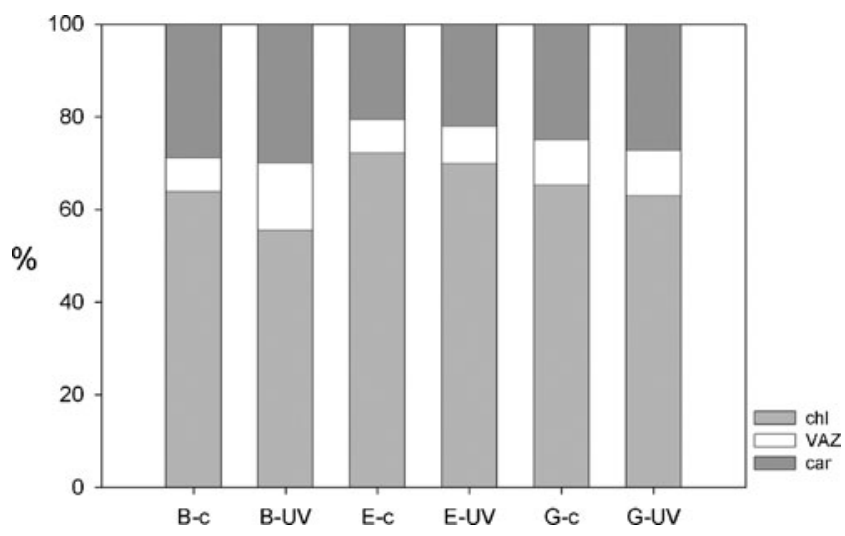

Figure 9 Proportion of individual pigment groups to the total chloroplast pigment content for each strain and treatment (mean values). $C h l$ chlorophylls $a$ and $b, V A Z$ violaxanthin, antheraxanthin and zeaxanthin (xanthophyll cycle pigments), car other primary carotenoids

The UV scenario created in our experiments did not reflect the natural solar spectrum, but included a shift in the ratio of UV to PAR, a method that is widely used for provoking UV effects in algae [e.g. 28, 31, 38, 52, 61, 63, 79]. Despite the experimental limitations, we found significant effects of UV treatment on the phenolic compounds in strain E. To our knowledge, this is the first study to use an HPLC protocol rather than spectrophotometric assays to quantify changes of phenolic compounds in streptophyte green algae after exposure to UV; recently, a red algal species, Hypnea, was investigated concerning phenolic compounds by HPLC [66].

\section{Phylogenetic Relationships}

One possible explanation for the differences observed among the investigated strains is their phylogenetic relationship. The species concept of the genus Zygnema, and in nearly all algae, is dominantly based on morphological characteristics [35], but it has been shown that traditional classification may not be consistent with phylogeny [71]. Further, the morphological distinction among Zygnema species rests on information from zygospores. Sexual reproduction was not observed in our strains and it was noted that other Zygnema from polar regions do not reproduce sexually $[31,40]$.

Therefore, the three strains under investigation were characterised by phylogenetic analysis of their $r b c \mathrm{~L}$ sequences. The genus Zygnema contains over 137 species. The systematics of only a small number of Zygnema species was recently clarified using analysis of $r b c \mathrm{~L}$ and $\operatorname{cox} 3$ data, but there are many species for which molecular data are not available [71]. Thus, we were unable to assign the strains used in this study to species. That said, the published sequences generated by this study should ultimately allow taxonomic assignment of the strains in the future and the information provided by these polar strains contributes to the understanding of the diversity and biology of the genus Zygnema. Interestingly, the two Arctic strains, Zygnema sp. $\mathrm{B}$ and $\mathrm{G}$, are not most closely related. Instead, Zygnema sp. $B$ is very closely related to the Antarctic strain (E) and to Zygnema cf. insigne.

\section{Structural and Ultrastructural Aspects}

Morphologically, samples of the three strains under control conditions looked similar. They all had a markedly condensed protoplasmic content and contained quite a high amount of small coloured bodies. Such a cytosolic appearance is not typical for young vegetative cells of Zygnema and resembles so-called pre-akinetes [46]. Many algae produce such modified vegetative cells by accumulating lipids and other metabolic products and by thickening the cell

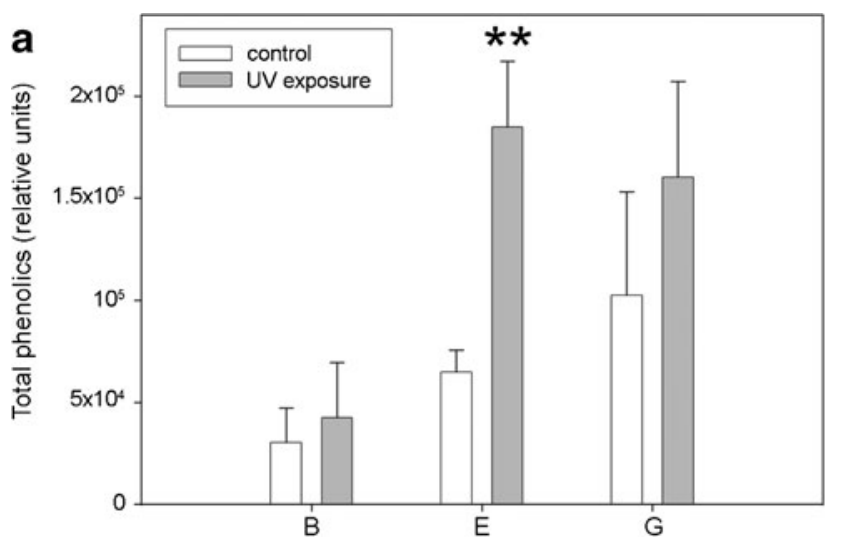

Figure 10 a Total content of phenolic compounds expressed as peak area per $1 \mathrm{mg}$ dry weight. Strain E control and 7-day UV-exposed samples differ significantly $(p=0.001)$ in their amount of phenolics, as indicated with two asterisks; the differences in the other strains are not significant ( $n=6$ for $\mathrm{E}$ and $\mathrm{G}, n=3$ for $\mathrm{B}$ ). Mean values $+\mathrm{SD}$.

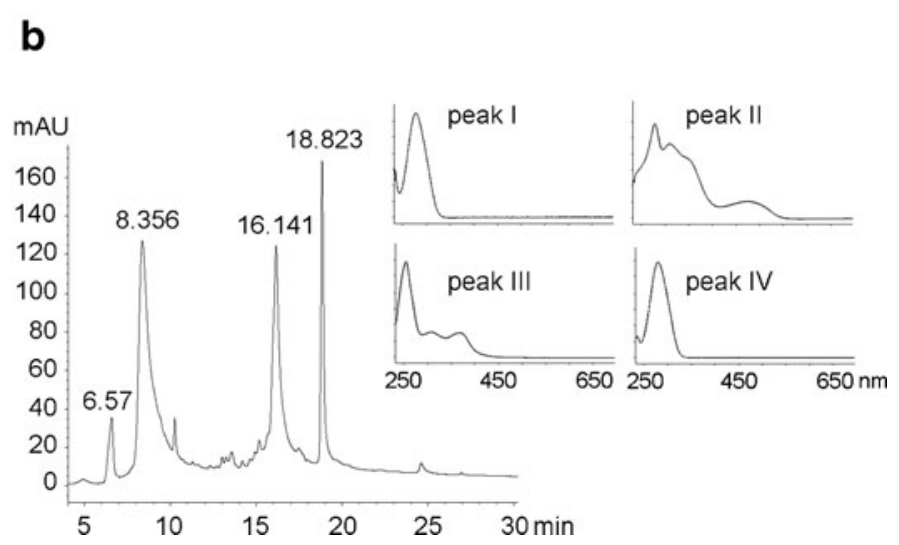

b Representative HPLC chromatogram at $280 \mathrm{~nm}$ of a UV-exposed culture $(E)$ revealing several different phenolic peaks. The control samples contained these compounds as well, only in lower concentrations per dry weight. Online absorption spectra of the four largest peaks are also given 
walls. Akinetes are formed at the onset of unfavourable conditions, such as nutrient starvation, and are considered resistant resting stages [15]. Markedly, natural populations of Zygnema sp. containing a high amount of lipid bodies have already been reported from the Arctic and Antarctica $[25,31]$. Also, the Zygnematophycean freshwater ice alga Mesotaenium berggrenii that survives harsh environmental conditions at glacier surfaces without making cysts contains high amounts of purpurogallin-derived, phenolic compounds [60]. It seems that such a cytology is an adaptation to extreme climatic conditions, where cells could be suddenly exposed to stress scenarios.

To date, a limited number of studies have addressed UV effects on the ultrastructure of freshwater algae from polar habitats [28, 31, 61], whereas red and brown algae are better studied (for a summary, see Karsten et al. [39]). The desmid Micrasterias denticulata was remarkably resistant to UV B; alterations in the ultrastructure were seen only as an effect of irradiation with wavelengths lower than $284 \mathrm{~nm}$ [44, 48].

The ultrastructural changes found in the present study as a consequence of UV exposure were moderate in strains B and $\mathrm{E}$, but pronounced in strain $\mathrm{G}$, where serious damage could be observed, especially in chloroplasts and mitochondria. Damage to these organelles is usually the first sign of UV-induced damage in sensitive species [24, 29]. While an earlier study on arctic Zygnema was made with fieldcollected samples followed by an exposure to an increased UV to PAR ratio only for $24 \mathrm{~h}$ [31], the present study employed cultivated samples exposed for 4 days to UV $\left(8 \mathrm{~h} \mathrm{day}^{-1}\right)$ irradiation. Moreover, all earlier studies used conventional chemical fixation $[28,31,61]$, but with the laboratory-grown samples, we were able to use sophisticated high-pressure freezing, followed by freeze substitution, a method that is generally accepted to allow better preservation of the ultrastructure.

We speculate that the electron-dense particles with a diameter of 400-600 nm frequently found in the cell cortex contain phenolics. These structures have a similar appearance like physodes, phlorotannin/phenolics containing structures frequently found in brown algae [26, 68, 69]. In the present study, most of these electron-dense particles appeared round, likely due to better preservation by highpressure freezing. In an earlier study, similar electron-dense structures with irregular outer shape, likely caused by shrinkage processes during dehydration, were detected in arctic Zygnema after chemical fixation [31]. We, therefore, assume that these substances are not lipids, as one could conclude by their electron density. Moreover, electron-dense structures have been described by McLean and Pessoney [46] as 'inclusions' in beginning akinetes of older Zygnema $\mathrm{sp}$. cultures. These structures were evident in untreated as well as in UV-treated cells in our study, which goes along with the finding that phenolics were also detected in both by
HPLC analysis, even after prolonged UV exposure. Moreover, the irregularly shaped medium electron-dense compartments in the cell cortex could contain phenolic compounds as well due to the hydrophilic nature of phenolics. However, we could not observe a quantitative enhancement of these medium electron-dense compartments in UV-exposed cells. The nature of these compartments remains obscure; they might either be some sort of lytic vacuoles, which could only be proven by investigating their contents. Due to the texture of these medium electron-dense compartments, one could even speculate that they are thylakoid-free parts of the chloroplast; however, we did not observe any connection of these compartments with the chloroplast.

There was little evidence for the accumulation of lipids based on TEM, which agrees with the observations of Bakker and Lokhorst [5], who also did not show accumulation of lipids in cultured Zygnema cells. This is in contrast to fieldgrown cells, which contain massive amounts of medium electron-dense bodies ('grey lipid bodies'), likely induced by nutrient starvation or harsh environmental conditions of the Arctic [31].

\section{Physiological Effects of UV Irradiation}

The presence of putative phenolic compounds was proven in all three Zygnema strains by using HPLC in control samples, as well as in 7-day UV-exposed samples; the prolonged exposure time in comparison to the TEM investigations had methodical reasons, but we speculate that this prolonged time caused only a quantitative increase in the amount of phenolics. This is in contrast to earlier reports, where only spectrophotometric assays (e.g. Folin-Ciocalteu) were used for a more imprecise determination [e.g. 18, 20, 41]. The presence of such phenolics, which are not common in freshwater microalgae, supports the hypothesis that their production might be crucial in UV protection of Zygnema. In all three strains, the mean value of total phenolic content rose after UV exposure. Nevertheless, only in strain E was this increase significant. The lack of significance in Zygnema sp. B and $G$ was mainly due to large variation in phenolic content among individual replicates. As a matter of fact, in strain $\mathrm{B}$, not enough biomass was available for more replications.

The screening effects of phenolics are enhanced by the fact that they are stored in electron-dense particles and vacuoles at the cell periphery, therefore protecting presumably chloroplasts and other organelles in the centre of the cells. This arrangement of organelles was confirmed in our Zygnema strains by TEM. High accumulation of secondary pigments in cytoplasmic compartments to shade the chloroplast was observed in other 
algae, too [29, 59]. Moreover, some of the phenolic compounds revealed in Zygnema also have an absorption in the VIS region, causing a yellowish to brownish colour of the vacuoles and of the aqueous extracts, respectively. Consequently, such compounds may also serve as protectants against excessive VIS irradiation, which otherwise could cause photoinhibition or intracellular ROS production. Stancheva et al. [71] found that zygotes of Zygnema exhibit a yellow, brownish or bluish secondary colouration, probably caused by such phenolic pigments. Strain E, which had the highest levels of phenolics after UV exposure, reached the highest values of $F_{\mathrm{V}} / F_{\mathrm{M}}$, suggesting a protective role of the phenolics for photosynthetic apparatus. Accordingly, the best photosynthetic rate (rETR) and $F_{\mathrm{V}} / F_{\mathrm{M}}$ values were found in cells of the chlorophyte Zygnemopsis decussata with high content of phenolics [18].

Remarkably, the strains investigated in this study also produced phenolic compounds without UV exposure; the values were highest in strain $G$, which could point towards influence by other stress. This indicates an accumulation in advance of any harmful irradiation events, probably similarly as in Zygogonium ericetorum, which exhibits pinkish vacuoles [32]. Phenolics are widely distributed in brown algae as phlorotannins $[1,16,50]$. In non-Streptophycean green algae, phenolics are not widespread, only few examples like the marine green alga Dasycladus vermicularis are known to contain phenolics [51]. In contrast, these compounds have been found in members of the Zygnematophyceae [12, 60], which might be explained by their close relationship to land plants $[6,77]$. In addition, a high amount of uncharacterised pigments was detected when attempting to isolate RNA from Z. cruciatum [22]. It could be speculated that these pigments were also phenolics, but there are many other compounds in the aqueous phase. Passive UV absorption is a nature of phenolic substances, given by their structure containing aromatic groups, but their original function in regards of plant physiology may be different [14]. Thus, the accumulation of phenolics is triggered not only by UV irradiation [50] but by different environmental factors (salinity, PAR and temperature) as well [51]. In fact, the applied temperature of $15{ }^{\circ} \mathrm{C}$ during the experiments could contribute to higher repair rates under these relatively low UV intensities.

In this study, a significant $(p<0.001)$ decrease of PS II efficiency was observed after UV exposure in strains $E$ and $\mathrm{G}$, but not in strain B. This parameter is widely used as an indicator of quantum efficiency of PS II photochemistry and gives a good measure of photoinhibitory damage caused by environmental stresses $[11,45]$. On the contrary, in the study of Holzinger et al. [31], no photoinhibition was observed at $926 \mu \mathrm{mol}$ photons $\mathrm{m}^{-2} \mathrm{~s}^{-1}$ in field-collected samples of Zygnema from Svalbard. Also, Germ et al. [20] showed no decrease in $F_{\mathrm{V}} / F_{\mathrm{M}}$ under UV B exposure. In other species, however, it has already been shown that UV exposure can result in a decline in $F_{\mathrm{V}} / F_{\mathrm{M}}$. Interestingly, some authors assign this to the effect of UV B $[52,79]$. In contrast, other authors conclude that it is UV A that directly affects PS II and causes inhibitory stress [18, 76], which could also be the case in this study, as we used a predominant UV A radiation treatment. UV exposure generated similar declines in Tetracystis sp. and Chlamydomonas nivalis, but the initial $F_{\mathrm{V}} / F_{\mathrm{M}}$ values were reached again after an overnight recovery [58].

All three investigated strains contained a considerable amount of antheraxanthin and zeaxanthin. The highest deepoxidation state of the xanthophyll cycle was found in strain $G$, which goes along with the highest levels of phenolics in control cells of this strain, which could as well be a consequence of other stress factors, already suppressing this strain prior to UV exposure. This argumentation would further be supported by the finding that strain $\mathrm{G}$ had the lowest values of $F_{\mathrm{V}} / F_{\mathrm{M}}$ in control cells. In the other strains, the deepoxidation was nearly $30 \%$ in strain B. This strain shows some signs of light stress, as the xanthophyll cycle pool size and the deepoxidation state increased; however, this was the only strain where UV treatment did not affect $F_{\mathrm{V}} / F_{\mathrm{M}}$ values significantly. The plastidal pigments were investigated, as quantitative changes could point towards intracellular stress events, e.g. chlorophyll degeneration or increase of xanthophyll cycle pigments. Moreover, with the same HPLC protocol, the presence or absence of any secondary carotenoids (e.g. astaxanthin) was tested and found to be negative. Xiong et al. [79] reported slight degradation of chlorophyll in UV B-sensitive green algal species. Such degradation products occurred in samples of Zygnema strain B and strain $G$ in the present study.

Other compounds may be involved in UV protection of Zygnema as well. No secondary carotenoids were detected, and MAAs have not been found in other Zygnematophyceae so far [60]. However, other ways of protection than producing intracellular compounds may play a role, and it has been suggested that extracellular structures help to screen UV (e.g. sporopollenin in the cell walls) [78]. Zygnema is capable of producing this resistant polymer, but its presence so far has been demonstrated only in the cell walls of zygospores [55]. Such putative substances may not have been extracted from the cell walls by our methods. Extracellular mucilage may also protect cells from UV [29]. Remarkably, in our study, the highest amount of mucilage production was observed in strain B. The presence of mucilage can also explain its significantly low amount of overall pigments per dry weight because a large proportion of dry weight 
was in fact due to extracellular matrix. Finally, another possibility for explaining UV tolerance may be the formation of macroscopic mats in the habitat, which is also typical for Zygnema [31]. Mat-forming growth forms provide self-shading and protect cells against excessive irradiation [9, 73].

\section{Conclusions}

Our study showed the accumulation of various phenolic-like compounds by polar, semi-terrestrial-derived Zygnema. The use of an HPLC protocol supported a reliable quantification than comparatively unspecific, colorimetric spectrophotometer assays. The phenolics are obviously involved in UV protection as significantly shown by the response of strain E. Even in Zygnema sp. strain G, which was severely stressed by the exposure conditions, a comparably high content of phenolics per dry weight was measured. The different strains, however, started under different physiological conditions. The lower optimal quantum yield in control cells of strain $\mathrm{G}$ in comparison to strains $\mathrm{B}$ and $\mathrm{E}$ could have influenced the UV resistance of this strain. It can be taken as a hint for another stress interacting with the UV in this strain, which is supported also by the very high deepoxidation state. However, it has to be stated that phenolic pigments generally play an important role in stress response of Zygnematophyceae, above all in species of extreme habitats like glacier surfaces [60], high mountain lakes [18] or semi-terrestrial habitats of polar regions as described in this study. In such locations, synthesis of phenolics has a substantial advantage - they are carbohydrates [21], which make their production 'cheaper' in comparison to, e.g. MAAs, containing nitrogen [13].

Our study gives evidence for the importance of phenolics in UV protection in Zygnema, but lacks a clear-cut correlation between the degree of damage and putative phenolic contents. Strain G shows damage in the ultrastructure and PS II quantum efficiency, but has as high phenolic content as strain $\mathrm{E}$ which did not show damage. On the other hand, strain B has the lowest total phenolics content and shows no signs of damage. This could have different reasons: First, it is possible that the applied UV intensities were too low to provoke significant UV damages in the investigated Zygnema strains. Second, the different responses to UV stress in the investigated Zygnema strains might as well suggest that various other strategies, such as mucilage production, compounds localised in the cell wall or mat-forming growth, might be involved in overall UV protection. This variation also illustrates the value in using more than a single isolate per genus or major taxon in physiological studies. There are great differences in ecophysiological performance among individual strains, and therefore, generalisations based on the investigation of a single strain might be misleading.

Further work is needed to compare the resistance of polar strains with that of algae from temperate or highaltitude regions where UV stress is naturally stronger. Moreover, to our knowledge, the structure of such phenolics occurring in Zygnema has not been determined. The isolation and characterisation of these compounds is currently under work. Finally, a detailed knowledge of special adaptation mechanisms in polar organisms may also be of potential use and commercial interest

Acknowledgements We thank Prof. Ursula Lütz-Meindl, University of Salzburg, Austria, for access to her high-pressure freezing device and Mag. Ancuela Andosch for the technical help in the high-pressure and freeze substitution process. Then, we would like to thank MSc. Siegfried Aigner, University of Innsbruck, and Shelley Olm, University of Connecticut, for the technical assistance. Prof. Jeffrey G. Duckett and Dr. Silvia Pressel, Natural History Museum, London, are acknowledged for helpful discussions. We also thank Dr. Tomáś Hájek, Academy of Sciences of the Czech Republic, for his advice on statistical analyses and valuable comments that improved the manuscript. The study was conducted during a research stay of M.P. at the University of Innsbruck funded by Österreichischer Austauschdienst scholarship (program AKTION). Support was granted as a long-term research development project of the Academy of Sciences of the Czech Republic RVO 67985939. The study was supported by the Tyrolean Science Fund (Project AP 717029) and the Austrian Science Fund (FWF-Project 24242) to A.H. and in part by the USA National Aeronautics and Space Administration (NASA) Exobiology NNX08AX20G grant to L.A.L.

Open Access This article is distributed under the terms of the Creative Commons Attribution License which permits any use, distribution, and reproduction in any medium, provided the original author(s) and the source are credited.

\section{References}

1. Abdala-Díaz RT, Cabello-Pasini A, Pérez-Rodríguez E, Conde Álvarez RM, Figueroa FL (2006) Daily and seasonal variations of optimum quantum yield and phenolic compounds in Cystoseira tamariscifolia (Phaeophyta). Mar Biol 148:459-465

2. Aichinger N, Lütz-Meindl U (2005) Organelle interactions and possible degradation pathways visualized in high-pressure frozen algal cells. J Microsc 219:86-94

3. Altschul SF, Gish W, Miller W, Myers EW, Lipman DJ (1990) Basic local alignment search tool. J Mol Biol 215:403-410

4. Arts MT, Robarts RD, Kasai F, Waiser MJ, Tumber VP, Plante AJ, Rai H, de Lange HJ (2000) The attenuation of ultraviolet radiation in high dissolved organic carbon waters of wetlands and lakes on the northern Great Plains. Limnol Oceanogr 45:292-299

5. Bakker ME, Lokhorst GM (1987) Ultrastructure of mitosis and cytokinesis in Zygnema sp. (Zygnematales, Chlorophyta). Protoplasma 138:105-118

6. Becker B, Marin B (2009) Streptophyte algae and the origin of embryophytes. Ann Bot 103:999-1004

7. Bischof K, Hanelt D, Wiencke C (2000) Effects of ultraviolet radiation on photosynthesis and related enzyme reactions of marine macroalgae. Planta 211:555-562 
8. Bischof K, Peralta G, Kräbs G, van de Poll WH, Pérez-Lloréns JL, Breeman AM (2002) Effects of solar UV-B radiation on canopy structure of Ulva communities from southern Spain. J Exp Bot 53:2411-2421

9. Bischoff HW, Bold HC (1963) Phycological studies IV. Some soil algae from Enchanted Rock and related algal species. Univ Texas Publ 6318:1-95

10. Blumthaler M (2007) Factors, trends and scenarios of UV radiation in arctic-alpine environments. In: Ørbæk JB, Kallenborn R, Tombre I, Hegseth EN, Falk-Petersen S, Hoel AH (eds) Arctic alpine ecosystems and people in a changing environment. Springer, Berlin, pp 181-193

11. Bolhár-Nordenkampf HR, Long SP, Baker NR, Öquist G, Schreiber U, Lechner EG (1989) Chlorophyll fluorescence as a probe of the photosynthetic competence of leaves in the field: a review of current instrumentation. Funct Ecol 3:497-514

12. Cannel RJ, Farmer P, Walker JM (1988) Purification and characterization of pentagalloylglucose, an alpha-glucosidase inhibitor/ antibiotic from the freshwater green alga Spirogyra varians. Biochem J 255:937-941

13. Carreto JI, Carignan MO (2011) Mycosporine-like amino acids: relevant secondary metabolites. Chemical and ecological aspects. Mar Drugs 9:387-446

14. Cockell CS, Knowland J (1999) Ultraviolet radiation screening compounds. Biol Rev Camb Philos Soc 74:311-345

15. Coleman AW (1983) The role of resting spores and akinetes in chlorophyte survival. In: Fryxell GA (ed) Survival strategies of the algae. Cambridge University Press, Cambridge, pp 1-21

16. Connan S, Goulard F, Stiger V, Deslandes E, Ar Gall E (2004) Interspecific and temporal variation in phlorotannin levels in an assemblage of brown algae. Bot Mar 47:410-416

17. Elster J (2002) Ecological classification of terrestrial algal communities of polar environment. In: Beyer L, Boelter M (eds) Geoecology of terrestrial oases, ecological studies, vol. 154. Springer, Berlin, pp 303-319

18. Figueroa FL, Korbee N, Carrillo P, Medina-Sánchez JM, Mata M, Bonomi J, Sánchez-Castillo PM (2009) The effects of UV radiation on photosynthesis estimated as chlorophyll fluorescence in Zygnemopsis decussata (Chlorophyta) growing in a high mountain lake (Sierra Nevada, Southern Spain). J Limnol 68:206-216

19. Garcia-Pichel F (1998) Solar ultraviolet and the evolutionary history of Cyanobacteria. Orig Life Evol Biosph 28:321-347

20. Germ M, Kreft I, Gaberščik A (2009) UV-B radiation and selenium affected energy availability in green alga Zygnema. Biologia 64:676-679

21. Graham LE, Kodner RB, Fisher MM, Graham JM, Wilcox LW, Hackney JM, Obst J, Bilkey PC, Hanson DT, Cook ME (2004) Early land plant adaptations to terrestrial stress: a focus on phenolics. In: Hemsley AR, Poole I (eds) The evolution of plant physiology. Elsevier Academic Press, Boston, pp 155-169

22. Han JW, Yoon M, Lee KP, Kim GH (2007) Isolation of total RNA from a freshwater green alga Zygnema cruciatum, containing high levels of pigments. Algae 22:125-129

23. Hanelt D, Tüg H, Bischof K, Gross C, Lippert H, Sawall T, Wiencke C (2001) Light regime in an Arctic fjord: a study related to stratospheric ozone depletion as a basis for determination of UV effects on algal growth. Mar Biol 138:649-658

24. Hanelt D, Wiencke C, Bischof K (2007) Effects of UV radiation on seaweeds. In: Ørbæk JB, Kallenborn R, Tombre I, Hegseth EN, Falk-Petersen S, Hoel AH (eds) Arctic alpine ecosystems and people in a changing environment. Springer, Berlin, pp 251-277

25. Hawes I (1990) Effects of freezing and thawing on a species of Zygnema (Chlorophyta) from the Antarctic. Phycologia 29:326-331

26. Hessen DO (2007) Effects of UV radiation in arctic and alpine freshwater ecosystems. In: Ørbæk JB, Kallenborn R, Tombre I, Hegseth EN, Falk-Petersen S, Hoel AH (eds) Arctic alpine ecosystems and people in a changing environment. Springer, Berlin, pp 211-225

27. Holzinger A, Di Piazza L, Lütz C, Roleda MY (2011) Sporogenic and vegetative tissues of Saccharina latissima (Laminariales, Phaeophyceae) exhibit distinctive sensitivity to experimentally enhanced ultraviolet radiation: photosynthetically active radiation ratio. Phycol Res 59:221-235

28. Holzinger A, Karsten U, Lütz C, Wiencke C (2006) Ultrastructure and photosynthesis in the supralittoral green macroalga Prasiola crispa from Spitsbergen (Norway) under UV exposure. Phycologia 45:168-177

29. Holzinger A, Lütz C (2006) Algae and UV irradiation: effects on ultrastructure and related metabolic functions. Micron 37:190-207

30. Holzinger A, Lütz C, Karsten U, Wiencke C (2004) The effect of ultraviolet radiation on ultrastructure and photosynthesis in the red macroalgae Palmaria palmata and Odonthalia dentata from Arctic waters. Plant Biol 6:568-577

31. Holzinger A, Roleda MY, Lütz C (2009) The vegetative arctic freshwater green alga Zygnema is insensitive to experimental UV exposure. Micron 40:831-838

32. Holzinger A, Tschaikner A, Remias D (2010) Cytoarchitecture of the desiccation-tolerant green alga Zygogonium ericetorum. Protoplasma 243:15-24

33. Huelsenbeck JP, Ronquist F (2001) MRBAYES: Bayesian inference of phylogenetic trees. Bioinformatics 17:754-755

34. Jones AE, Shanklin JD (1995) Continued decline of total ozone over Halley, Antarctica, since 1985. Nature 376:409-411

35. Kadlubowska JZ (1984) Conjugatophyceae I: Chlorophyta VIII: Zygnemales. In: Ettl H, Gerloff J, Heynig H, Mollenhauer D (eds) Süsswasserflora von Mitteleuropa, Band 16. Gustav Fischer, Jena, pp $1-532$

36. Kaplan F, Lewis LA, Wastian J, Holzinger A (2012) Plasmolysis effects and osmotic potential of two phylogenetically distinct alpine strains of Klebsormidium (Streptophyta). Protoplasma 249:789-804

37. Karsten U, Dummermuth A, Hoyer K, Wiencke C (2003) Interactive effects of ultraviolet radiation and salinity on the ecophysiology of two Arctic red algae from shallow waters. Polar Biol $26: 249-258$

38. Karsten U, Lembcke S, Schumann R (2007) The effects of ultraviolet radiation on photosynthetic performance, growth and sunscreen compounds in aeroterrestrial biofilm algae isolated from building facades. Planta 225:991-1000

39. Karsten U, Wulff A, Roleda MY, Müller R, Steinhoff FS, Fredersdorf J, Wiencke C (2011) Physiological responses of polar benthic micro- and macroalgae to ultraviolet radiation. In: Wiencke C (ed) Biology of polar benthic algae. Walter de Gruyter, Berlin, pp 271-297

40. Kim GH, Klotchkova TA, Kang SH (2008) Notes on freshwater and terrestrial algae from Ny-Ålesund, Svalbard (high Arctic sea area). J Env Biol 29:485-491

41. Kováčik J, Klejdus B, Bačkor M (2010) Physiological responses of Scenedesmus quadricauda (Chlorophyceae) to UV-A and UV-C light. Photochem Photobiol 86:612-616

42. Lemoine Y, Schoefs B (2010) Secondary ketocarotenoid astaxanthin biosynthesis in algae: a multifunctional response to stress. Photosynth Res 106:155-177

43. Lewis LA, Mishler BD, Vilgalys R (1997) Phylogenetic relationships of the liverworts (Hepaticae), a basal embryophyte lineage, inferred from nucleotide sequence data of the chloroplast gene, rbcL. Mol Phylog Evol 7:377-393

44. Lütz C, Seidlitz HK, Meindl U (1997) Physiological and structural changes in the chloroplast of the green alga Micrasterias denticulata induced by UV-B simulation. Plant Ecol 128:55-64

45. Maxwell K, Johnson GN (2000) Chlorophyll fluorescence-a practical guide. J Exp Bot 51:659-668 
46. McLean RJ, Pessoney GF (1971) Formation and resistance of akinetes of Zygnema. In: Parker BC, Brown RM Jr (eds) Contributions in phycology. Allen, Lawrence, pp 145-152

47. McManus H, Lewis L (2011) Molecular phylogenetic relationships in the freshwater family Hydrodictyaceae (Sphaeropleales, Chlorophyceae), with an emphasis on Pediastrum duplex. J Phycol 47:152-163

48. Meindl U, Lütz C (1996) Effects of UV irradiation on cell development and ultrastructure of the green alga Micrasterias. J Photochem Photobiol B Biol 36:285-292

49. Müller R, Crutzen PJ, Grooss J-U, Brühl C, Russell JM III, Gernandt H, McKenna DS, Tuck AF (1997) Severe chemical ozone loss in the Arctic during the winter of 1995-96. Nature 389:709-712

50. Pavia H, Cervin G, Lindgren A, Aberg P (1997) Effects of UV-B radiation and simulated herbivory on phlorotannins in the brown alga Ascophyllum nodosum. Mar Ecol Progr Ser 157:139-146

51. Pérez-Rodríguez E, Aguilera J, Gómez Y, Figueroa FL (2001) Excretion of coumarins by the Mediterranean green alga Dasycladus vermicularis in response to environmental stress. Mar Biol 139:633-639

52. Pescheck F, Bischof K, Bilger W (2010) Screening of ultraviolet-A and ultraviolet-B radiation in marine green macroalgae (Chlorophyta). J Phycol 46:444-455

53. Poppe F, Hanelt D, Wiencke C (2002) Changes in ultrastructure, photosynthetic activity and pigments in the Antarctic red alga Palmaria decipiens during acclimation to UV radiation. Bot Mar 45:253-261

54. Posada D (2008) jModelTest: phylogenetic model averaging. Mol Biol Evol 25:1253-1256

55. Poulíčková A, Žižka Z, Hašler P, Benada O (2007) Zygnematalean zygospores: morphological features and use in species identification. Folia Microbiol 52:135-145

56. Rambaut A, Drummond AJ (2003) Tracer: MCMC trace analysis tool. University of Oxford, Oxford

57. Remias D, Lütz-Meindl U, Lütz C (2005) Photosynthesis, pigments and ultrastructure of the alpine snow alga Chlamydomonas nivalis. Eur J Phycol 40:259-268

58. Remias D, Albert A, Lütz C (2010) Effects of realistically simulated, elevated UV irradiation on photosynthesis and pigment composition of the alpine snow alga Chlamydomonas nivalis and the arctic soil alga Tetracystis sp. (Chlorophyceae). Photosynthetica 48:269-277

59. Remias D, Holzinger A, Aigner S, Lütz C (2012) Ecophysiology and ultrastructure of Ancylonema nordenskiöldii (Zygnematales, Streptphyta), causing brown ice on glaciers in Svalbard (high Arctic). Polar Biol 35:899-908

60. Remias D, Schwaiger S, Aigner S, Leya T, Stuppner H, Lütz C (2012) Characterization of an UV- and VIS-absorbing, purpurogallin-derived secondary pigment new to algae and highly abundant in Mesotaenium berggrenii (Zygnematophyceae, Chlorophyta), an extremophyte living on glaciers. FEMS Microbiol Ecol 79:638-648

61. Roleda MY, Lütz-Meindl U, Wiencke C, Lütz C (2010) Physiological, biochemical and ultrastructural responses of the green macroalga Urospora penicilliformis from Arctic Spitsbergen to UV radiation. Protoplasma 243:105-116

62. Schmidt EC, Scariot LA, Rover T, Bouzon ZL (2009) Changes in ultrastructure and histochemistry of two red macroalgae strains of Kappaphycus alvarezii (Rhodophyta, Gigartinales) as a consequence of ultraviolet B radiation exposure. Micron 40:860-869
63. Schmidt EC, dos Santos R, Horta PA, Maraschin M, Bouzon ZL (2010) Effects of UVB radiation on the agarophyte Graciliaria domingensis (Rhodophyta, Gracilariales): changes in cell organization, growth and photosynthetic performance. Micron 41:919-930

64. Schmidt EC, Maraschin M, Bouzon ZL (2010) Effects of UVB radiation on the carragenophyte Kappaphycus alvarezii (Rhodophyta, Gigartinales): changes in ultrastructure, growth, and photosynthetic pigments. Hydrobiologia 649:171-182

65. Schmidt EC, Nunes BG, Maraschin M, Bouzon ZL (2010) Effect of ultraviolet-B radiation on growth, photosynthetic pigments, and cell biology of Kappaphycus alvarezii (Rhodophyta, Gigartinales) macroalgae brown strain. Photosynthetica 48:161-172

66. Schmidt EC, Pereira B, Santos R, Gouveia C, Costa GB, Faria GSM, Scherner F, Horta PA, Paula MR, Latini A, Ramlov F, Maraschin M, Bouzon ZL (2012) Responses of the macroalga Hypnea musciformis after in vitro exposure to UV-B. Aquat Bot 100:8-17

67. Schmidt EC, Pereira B, Pontes CL, dos Santos R, Scherner F, Horta PA, de Paula MR, Latini A, Maraschin M, Bouzon ZL (2012) Alterations in architecture and metabolism induced by ultraviolet radiation-B in the carrogenophyte Chondracanthus teedei (Rhodophyta, Gigartinales). Protoplasma 249:353-367

68. Schoenwaelder MEA (2002) The occurrence and cellular significance of physodes in brown algae. Phycologia 41:125-139

69. Schoenwaelder MEA, Clayton MN (1998) Secretion of phenolic substances into the zygote wall and cell plate in embryos of Hormosira and Acrocarpia (Fucales, Phaeophyceae). J Phycol 34:969-980

70. Scully NM, Lean DRS (1994) The attenuation of UV radiation in temperate lakes. Arch Hydrobiol 43:135-144

71. Stancheva R, Hall JD, Sheath RG (2012) Systematics of the genus Zygnema (Zygnematophyceae, Charophyta) from Californian watersheds. J Phycol 48:409-422

72. Swofford DL (2002) PAUP*, version 4b10. Sinauer Associates, Sunderland

73. Tanabe Y, Ohtani S, Kasamatsu N, Fukuchi M, Kudoh S (2010) Photophysiological responses of phytobenthic communities to the strong light and UV in Antarctic shallow lakes. Polar Biol 33: $85-100$

74. Thomas DN, Fogg GE, Convey P, Fritsen CH, Gili J-M, Gradinger R, Laybourn-Parry J, Reid K, Walton DWH (2008) The biology of polar regions. Oxford University Press, Oxford

75. Wessel S, Aoki S, Winkler P, Weller R, Herber A, Gernandt H, Schrems O (1998) Tropospheric ozone depletion in polar regionsa comparison of observations in the Arctic and Antarctic. Tellus B 50:34-50

76. White AL, Jahnke LS (2002) Contrasting effects of UV-A and UV$\mathrm{B}$ on photosynthesis and photoprotection of beta-carotene in two Dunaliella spp. Plant Cell Physiol 43:877-884

77. Wodniok S, Brinkmann H, Glöckner G, Heidel AJ, Philippe H, Melkonian M, Becker B (2011) Origin of land plants: do conjugating green algae hold the key? BMC Evol Biol 11:104

78. Xiong F, Komenda J, Kopecký J, Nedbal L (1997) Strategies of ultraviolet-B protection in microscopic algae. Physiol Plant 100:378-388

79. Xiong F, Kopecký J, Nedbal L (1999) The occurrence of UV-B absorbing mycosporine-like amino acids in freshwater and terrestrial microalgae (Chlorophyta). Aquat Bot 63:37-49 